\title{
GLINICAL PROFILE AND PREDICTORS OF MORTALITY IN PATIENTS ADMITTED WITH COVID-19 IN A TERTIARY GARE HOSPITAL
}

\author{
Syed Vaqar Ahmad Shah, ${ }^{1}$ Farmud Ansari, ${ }^{2}$ Sayed Sartaj Sohrab, ${ }^{3}$ Kadir Alam, ${ }^{4}$ \\ Deependra Prasad Sarraft
}

${ }^{1}$ Department of Internal Medicine \& ${ }^{2}$ Department of Internal Medicine and Pulmonology, Nobel Medical College Teaching Hospital, Biratnagar, Nepal, ${ }^{3}$ Department of Medical Laboratory Sciences, Faculty of Applied Medical Sciences, King

Abdulaziz University, P.O. Box 80216, Jeddah 21589, Saudi Arabia, ${ }^{4}$ Department of Clinical Pharmacology and Therapeutics, B.P. Koirala Institute of Health Sciences, Dharan, Nepal

\section{ABSTRACT}

Hospitalization and survival rate in patients with coronavirus disease 2019 (COVID-19) is affected by pre-existing chronic medical conditions and the disease severity. The objectives of the study were to describe the baseline clinical profile, co-morbidities, disease severity and to assess the predictors of mortality in hospitalized adult patients with COVID-19 in a tertiary care hospital in Nepal. A cross-sectional study was conducted for two months on 168 adult COVID-19 patients admitted to Nobel Medical College Teaching Hospital Biratnagar. Demographics, comorbidities, disease severity, oxygen requirement, and treatment outcomes were studied. The mean age of the patients was 57.1 years and $56.5 \%$ were male. Out of $168,16.7 \%$ and $10.1 \%$ of the participants had currently or in the past used alcohol or tobacco products respectively. Hypertension (28.6\%) and chronic lung disease (16.1\%) were the most common co-morbidities. The overall case-fatality rate was $17.9 \%$, with $32.1 \%$ and $56.3 \%$ in the severe and critical COVID-19 subgroup respectively. The mortality rate for patients without co-morbidities was $2.4 \%$ which increased to $63.6 \%$ for those with three or more co-morbidities. Age, disease severity, and the number of co-morbidities were found to be associated with increased mortality $(\mathrm{P}<0.05)$, whereas gender was not. The preexisting chronic diseases and increased severity of the disease were associated with increased mortality in hospitalized COVID-19 adult patients.

\section{KEYWORDS}

Comorbidity, COVID-19, Hospitalization, Mortality

Received on: August 29, 2021

Accepted for publication: October 28, 2021

\section{CORRESPONDING AUTHOR}

Dr. Syed Vaqar Ahmad Shah

Assistant Professor,

Department of Internal Medicine

Nobel Medical College and Teaching Hospital

Biratnagar, Nepal

Email: svaqarahmad@hotmail.com

Orcid No: https://orcid.org/0000-0003-0925-9089

DOI: https://doi.org/10.3126/nmcj.v23i4.42259 


\section{INTRODUCTION}

An outbreak of unusual pneumonia caused by novel coronavirus was observed in hospitalized patients from Wuhan, China in December 2019. This virus spread to the rest of the world represented a great threat to global health. ${ }^{1,2}$ The causative agent was identified and it was designated as severe acute respiratory syndrome coronavirus 2 (SARS-CoV-2) based on the genomic sequences, phylogenetic relationship, and high sequences similarity with bat coronavirus (SARS-bat virus). The disease caused by it was named as COVID-19 in February 2020 and pandemic was declared on March 11,2020.,4 This virus belongs to the family Coronaviridae, with positive sense, ssRNA virus with an approximately 26 to $32 \mathrm{~kb}$ genome. Currently, this virus has spread to more than 220 countries and territories with 210,212,244 cases, with 4,407,224 deaths and 188,306,903 recoveries. The clinical symptoms of COVID-19 varied from asymptomatic infection to severe acute respiratory syndrome (SARS), with high mortality rates of approximately $2-5 \%$. Acute respiratory distress syndrome (ARDS) induced by viral pneumonia attributed the mortality caused by COVID-19 infections. ARDS represents the most serious complication of SARS-2 infection with a mortality rate ranging from 26-94\% globally. ${ }^{4,5}$ Based on the recent publications, an atypical manifestation of the disease characterized by an exaggerated inflammatory and increased incidence of shock and distinct phenotype characterized by higher respiratory compliance with extensive radiographic abnormalities have been described. There are limited treatment options for COVID-19 induced ARDS. The clinical features, death predictors, outcomes and factors associated with the progression of COVID-19 disease and mortality has been described in many recent publications. ${ }^{5-14}$ The clinical presentation of COVID-19 can range from asymptomatic cases diagnosed during contact tracing, mild to moderately symptomatic patients managed at home, or those that require hospitalization. Several studies have reported alterations in various biochemical parameters among COVID-19 patients and they have been identified as important clinical predictors for the severity of SARS-CoV-2 infection. Currently, the management and treatment guidelines mainly focused on vaccination, prevention, control, and supportive intensive care involving oxygen supplementation and mechanical ventilation as required. Although the first case of COVID-19 was reported in Nepal on a student returning from the epicenter Wuhan, China, in January $2020,{ }^{15}$ there is a paucity of data regarding the clinical profile of the patients requiring hospitalization in the country. Despite only a small proportion of patients requiring admission, the knowledge regarding the clinical profile and predictors of mortality in hospitalized patients can help manage such cases.

This study focuses to investigate the baseline characteristics, their comorbidities, the requirement of supplemental oxygen therapy and treatment outcome of adult patients admitted to Nobel Medical College Teaching Hospital during the second peak of the COVID-19 pandemic.

\section{MATERIALS AND METHODS}

A cross-sectional study was conducted among adult patients admitted with a diagnosis of COVID-19 confirmed by real-time polymerase chain reaction (RT-PCR) on nasopharyngeal and/or oropharyngeal swab specimens from $1^{\text {st }}$ May 2021 to $30^{\text {th }}$ June 2021 in Nobel Medical College, Nepal. The relevant data were collected from the discharge summary and case files of the patients after taking the informed consent from the patient or their next of kin. The data included age, sex, co-morbidities, baseline characteristics, the severity of the disease, treatment including supplemental oxygen therapy and the outcome. The sample size was estimated as:

$$
\begin{aligned}
& \mathrm{n}=\mathrm{Z}^{2} \times \mathrm{p} \times(1-\mathrm{p}) / \mathrm{e}^{2} \\
& =1.96^{2} \times 0.11 \times(1-0.11) /(0.05)^{2} \\
& =151 \\
& \text { where, }
\end{aligned}
$$

$\mathrm{n}=$ minimum required sample size

$\mathrm{Z}=1.96$ at $95 \%$ confidence interval

$\mathrm{p}=$ mortality rate in hospitalized patients,

$0.11^{16}$

$\mathrm{e}=$ margin of error, 0.05

The required sample size was 151 . Accounting for a non-response of $10 \%$ the minimum sample size needed was 166 . The total number of participants in our study was 168.

The severity of the disease was based on the World Health Organization (WHO) COVID-19 disease severity categorization which includes: 1) critical COVID-19, defined by the presence of SARS, sepsis, septic shock, or other condition requiring life-sustaining therapies; 2) severe COVID-19, defined by oxygen saturation less than $90 \%$ on ambient air, increased respiratory rate, signs of severe respiratory distress or the presence of any danger signs; and 3) nonsevere COVID-19, defined by cases not meeting the above definition. ${ }^{17}$

The data thus collected were entered in Microsoft Excel 2007 and subsequently analysed using IBM SPSS version 20. The categorical data were compared using Chi-square tests 
and continuous data were compared using Student's t-test. A P-value $<0.05$ was considered significant with a 95\% confidence interval. The ethical clearance was taken from the Institutional Review Committee of Nobel Medical College (IRC NMCTH 507/2021).

\section{RESULTS}

A total of 168 adult patients were hospitalized with COVID-19 during the study period. The mean age of the patients was 57.1 years and 95 $(56.5 \%)$ were male. Age of the patients ranged from 19-90 years. Seventeen patients (10.1\%) were current/past tobacco users. Hypertension (28.6\%) was the most common co-morbidity followed by chronic lung disease (16.1\%) and diabetes mellitus (14.3\%) (Table 1).

\begin{tabular}{|llc|}
\hline \multicolumn{3}{|c|}{$\begin{array}{c}\text { Table 1: Baseline characteristics of the } \\
\text { COVID-19 patients (n=168) }\end{array}$} \\
\begin{tabular}{|llc|} 
Variables & & n (\%) \\
\hline \multirow{2}{*}{ Gender } & Male & $95(56.5)$ \\
& Female & $73(43.5)$ \\
\hline \multirow{2}{*}{ Age } & Mean & 57.1 years \\
& Range & $19-90$ years \\
\hline Current/ & Alcohol & $28(16)$ \\
Former use of & Tobacco products & $17(10.1)$ \\
\hline \multirow{4}{*}{ Co-morbidities } & Hypertension & $48(28.6)$ \\
& Chronic lung & $27(16.1)$ \\
& Diabeases & $24(14.3)$ \\
& Renal disorder & $16(9.5)$ \\
& Cardiac disease & $13(7.7)$ \\
\hline
\end{tabular}
\end{tabular}

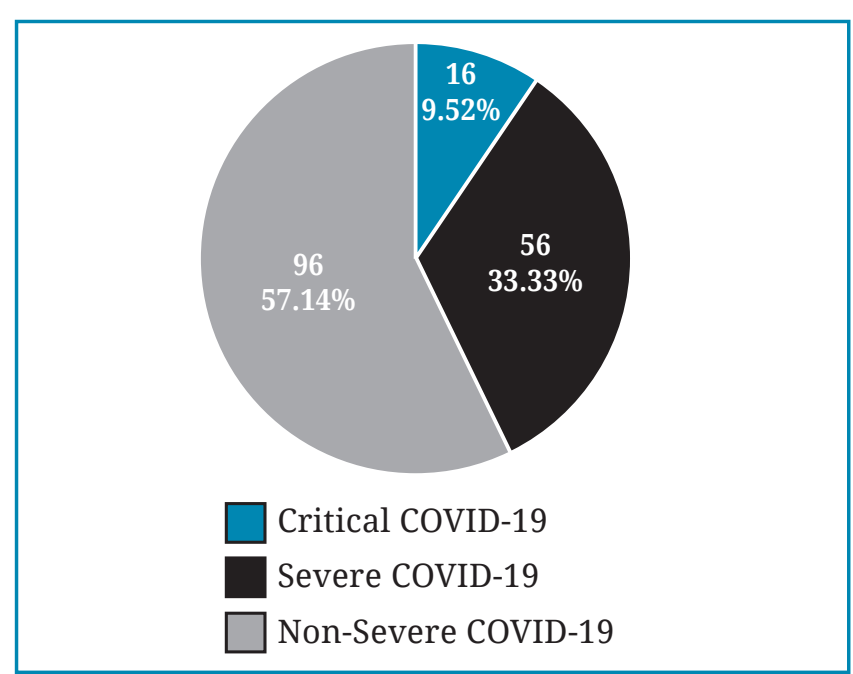

Fig. 1: The severity of COVID-19 in admitted patients $(\mathrm{n}=168)$

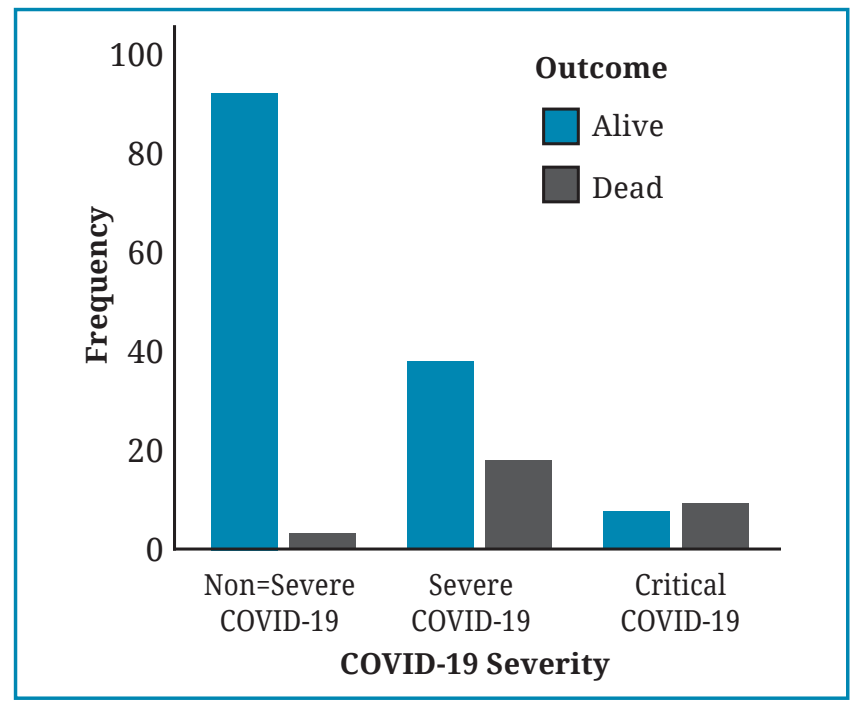

Fig. 2: Clustered bar chart showing the outcome of participants according to the disease severity $(n=168)$

\begin{tabular}{|c|c|c|c|}
\hline Variable & & Frequency (\%) & P-value \\
\hline \multirow{3}{*}{ Age group } & $<40$ years & $1(4)$ & \multirow{3}{*}{0.02} \\
\hline & $40-60$ years & $9(13.8)$ & \\
\hline & $>60$ years & $20(25.6)$ & \\
\hline \multirow{2}{*}{ Gender } & Male & $15(15.8)$ & \multirow{2}{*}{0.42} \\
\hline & Female & $15(20.5)$ & \\
\hline \multirow{2}{*}{$\begin{array}{l}\text { Supplemental oxygen } \\
\text { requirement }\end{array}$} & Not required & $0(0)$ & \multirow{2}{*}{0.04} \\
\hline & Required & $30(20.0)$ & \\
\hline \multirow{3}{*}{ Severity of COVID-19 } & Non-severe COVID-19 & $18(32.1)$ & \multirow{3}{*}{0.001} \\
\hline & Severe COVID-19 & $9(56.3)$ & \\
\hline & Critical COVID-19 & $3(3.1)$ & \\
\hline \multirow{4}{*}{$\begin{array}{l}\text { Number of co- } \\
\text { morbidities }\end{array}$} & None & $2(2.4)$ & \multirow{4}{*}{0.001} \\
\hline & One Co-morbidity & $9(16.7)$ & \\
\hline & Two Co-morbidities & $12(57.1)$ & \\
\hline & Three Co-morbidities & $7(63.6)$ & \\
\hline
\end{tabular}


Out of 168, 16 (9.5\%) patients had critical COVID-19 whereas 56 (33.3\%) had severe COVID-19 as defined by the WHO COVID-19 severity criteria. ${ }^{17}$ One hundred and fifty (89.3\%) patients required supplemental oxygen therapy (Fig. 1).

The case fatality rate for the hospitalized patients was $17.9 \%$. The mean age of the participants that died was 63.4 years as compared to 55.7 years of the recovery group. Furthermore, it was observed that participants with increased age had decreased survival with a mortality rate of $4 \%$ in participants below 40 years compared to $25.6 \%$ in those above 60 years of age. There were significant differences in the case fatality rate for various severity of the disease. Nine patients (56.3\%) with critical COVID-19 expired whereas only three (3.1\%) non-severe COVID-19 patients died (Fig. 2).

Similarly, the presence of co-morbidities in the form of previous illness also increased the likelihood of death as evidenced by $63.6 \%$ of the patients with three diseases dying compared to the mortality rate of only $2.4 \%$ in patients without any prior comorbidity (Table 2). The clinical predictors of mortality in hospitalized adult patients with COVID-19 were age, disease severity, oxygen requirement and the presence of co-morbidities.

\section{DISCUSSION}

The COVID-19 disease has become more challenging for low income countries with poor healthcare facility including Nepal. We have presented the clinical and outcome data for 168 hospitalized and confirmed COVID-19 participants based on cross-sectional study looked at the relationship between the presence of co-morbidities, the severity of the disease, and outcome at Nobel Medical College Teaching Hospital Biratnagar, Nepal. The average age of the participant was 57.1 years with majority of male patients. This finding was similar to the one reported in a tertiary cardiovascular center in the country. ${ }^{16}$ The comorbidities reported in this study were also similar to the findings of Gold et $a l^{18}$ and Bajgain et $a l^{19}$ in which hypertension, diabetes mellitus, chronic obstructive pulmonary disease and renal disorder were also the most common comorbidities. Hypertension made up the most common co-morbidity in this study at $27.4 \%$, similar to our finding (28.4\%). The number of participants with multiple comorbidities was higher in our study as compared to a study done in hospitalized Indian patients by Padmaprakash et al. ${ }^{20}$ Moreover, it was noted in our study that patients with an increased number of comorbidities had a poorer outcome.
Surendra et al also reported similar findings in hospitalized patients in Indonesia. ${ }^{21}$

The overall mortality rate noted in our study was $17.9 \%$ which was higher than that reported in other studies. However, a direct comparison could not be made due to the heterogeneity in the severity of COVID-19 patients in our study when compared to other reports. A similar study done in Mexico City by Olivas-Martínez et al found the mortality rate for severe COVID-19 patients to be $30.1 \% .{ }^{22}$ The combined mortality rate for the severe and critical COVID-19 patients was $37.5 \%$ in our study. This variation in the mortality rate could be explained by older patients in the study, multiple co-morbidities in the participants, study being conducted during the peak of the second wave where the resources were constrained. A similar observation was also made in the study by Olivas-Martínez et $a .^{22}$ In many another reports, the mortality rate was higher than the European population and in Chinese cohorts study the overall cases were higher in men than women. ${ }^{9-12,23-25}$ The COVID-19 infection also induces the cytokine storm and lymphopenia, resulting into high cytokine levels (IL-2 receptor, IL-6, IL-8, IL-10) and necrosis factor (TNF $\alpha$ ) which explains the result of multi-organ failure. ${ }^{26}$

The clinical predictors of mortality noted in the study viz, age, oxygen requirement, disease severity, and the number of chronic diseases were also corroborated by an Indian study. ${ }^{20}$ However, unlike the finding of that study, gender was not a predictor of mortality in our study. But there are some studies from China, UK, USA, and Spain have reported the male gender was predominant predictor of mortality. ${ }^{9-12,23-25}$

Limitations: The present study has some limitations. It was conducted over two months during the peak of the COVID-19 pandemic, so the findings in this study could have been affected by resources constraint. As it was a single-centerd study, the finding of which needs to be concurred by other studies in a similar setting. This study also did not look at the participants requiring ICU admission and ventilatory support separately to account for their impact on survival. A detailed and comprehensive study may be necessary to understand the COVID-19 patients in other regions with a greater number of samples so that a significant difference with patients can be established in other regions.

This study highlighted the clinical profile of hospitalized COVID-19 patients and demonstrated the impact of age, pre-existing disease conditions and COVID-19 severity as predictors of mortality in these patients. 


\section{ACKNOWLEDGEMENTS}

We would like to thank all the study participants.

Conflict of interest: None

Source of research fund: None

\section{REFERENCES}

1. WHO Statement Regarding Cluster of Pneumonia Cases in Wuhan, China. Available at: https://www.who.int/china/news/detail/0901-2020-who-statement-regarding-cluster-ofpneumonia-cases-in-wuhan-china. Accessed on September 6, 2021.

2. Zhou M, Zhang X, Qu J. Coronavirus disease 2019 (COVID-19): a clinical update. Frontiers Med 2020; 14: 126-35.

3. World Health Organization. Director-General's Remarks at the Media Briefing on 2019nCoV on 11 February 2020. Available from: https://scirp.org/reference/referencespapers. aspx?referenceid=3017558. Accessed on September 6, 2021.

4. WHO Director-General's opening remarks at the media briefing on COVID-19 - 11 March 2020. Available at: https://www.who.int/directorgeneral/speeches/detail/who-director-generals-opening-remarks-at-the-media-briefing-oncovid-19-11-march-2020. Accessed on September 6, 2021.

5. Azoulay E, Fartoukh M, Darmon M, et al. Increased mortality in patients with severe SARS-CoV-2 infection admitted within seven days of disease onset. Intensive Care Med 2020; 46: 1714-22.

6. Wu C, Chen X, Cai Y, et al. Risk factors associated with acute respiratory distress syndrome and death in patients with coronavirus disease 2019 pneumonia in Wuhan, China. JAMA Int Med 2020; 180: 934.

7. Wendel Garcia P, Fumeaux T, Guerci P, et al. Prognostic factors associated with mortality risk and disease progression in 639 critically ill patients with COVID-19 in Europe: Initial report of the international RISC-19-ICU prospective observational cohort. E Clin Med 2020; 25: 100449.

8. Jang J, Hur J, Choi E, Hong K, Lee W, Ahn J. Prognostic factors for severe coronavirus disease 2019 in Daegu, Korea. J Korean Med Sci 2020; 35.

9. El-Solh AA, Meduri UG, Lawson Y, Carter M, Mergenhagen KA. Clinical course and outcome of COVID-19 acute respiratory distress syndrome: Data from a national repository. J Int Care Med 2021; 36: 664-72.

10. Gutiérrez-Abejón E, Martín-García D, Tamayo E, Álvarez FJ, Herrera-Gómez F. Clinical profile, pharmacological treatment, and predictors of death among hospitalized COVID-19 patients with acute kidney injury: a population-based registry analysis. Front Med 2021; 8.
11. Gutiérrez-Abejón E, Tamayo E, Martín-García D, Álvarez FJ, Herrera-Gómez F. Clinical profile, treatment and predictors during the first covid-19 wave: a population-based registry analysis from Castile and Leon hospitals. Int $J$ Environ Res Public Health 2020; 17: 9360.

12. Ahsan T, Rani B, Siddiqui R, et al. Clinical variants, characteristics, and outcomes among COVID-19 patients: a case series analysis at a tertiary care hospital in Karachi, Pakistan. Cureus 2021; 13(4).

13. Perez Guzman P, Daunt A, Mukherjee S. Clinical characteristics and predictors of outcomes of hospitalised patients with COVID-19 in a London NHS Trust: a retrospective cohort study. London: Imperial College Healthcare NHS Trust 2020; 29.

14. Ayisi-Boateng NK, Owusu M, Tawiah $\mathrm{P}$, et al. Profile and outcomes of hospitalized patients with COVID-19 at a tertiary institution hospital in Ghana. Ghana Med J 2020; 54: 39-45.

15. Bastola A, Sah R, Rodriguez-Morales AJ, et al. The first 2019 novel coronavirus case in Nepal. Lancet Infect Dis 2020; 20: 279-80.

16. Siemieniuk R, Rochwerg B, Agoritsas T, et al. A living WHO guideline on drugs for covid-19. BMJ 2020;370:m3379.

17. Gold MS, Sehayek D, Gabrielli S, Zhang X, McCusker C, Ben-Shoshan M. COVID-19 and comorbidities: a systematic review and metaanalysis. Postgrad Med 2020; 132: 749-55.

18. Bajgain KT, Badal S, Bajgain BB, Santana MJ. Prevalence of comorbidities among individuals with COVID-19: A rapid review of current literature. Am J Infect Control 2021; 49: 238-46.

19. Padmaprakash KV, Vardhan V, Thareja S, et al. Clinical characteristics and clinical predictors of mortality in hospitalised patients of COVID 19: An Indian study. Med J Armed Forces India 2021; 77: S319-32.

20. Surendra H, Elyazar IR, Djaafara BA, et al. Clinical characteristics and mortality associated with COVID-19 in Jakarta, Indonesia: a hospitalbased retrospective cohort study. Lancet Reg Health West Pac 2021; 9: 100108.

21. Olivas-Martínez A, Cárdenas-Fragoso JL, Jiménez JV, et al. In-hospital mortality from severe COVID-19 in a tertiary care center in Mexico City; causes of death, risk factors and the impact of hospital saturation. Plos One 2021; 16: e0245772.

22. Guan WJ, Ni ZY, Hu Y, et al. Clinical characteristics of coronavirus disease 2019 in China. New Eng J Med 2020; 382: 1708-20.

23. Chen $\mathrm{T}$, $\mathrm{Wu} \mathrm{DI}$, Chen $\mathrm{H}$, et al. Clinical characteristics of 113 deceased patients with coronavirus disease 2019: retrospective study. BMJ 2020; 368.

24. Onder G, Rezza G, Brusaferro S. Case-fatality rate and characteristics of patients dying in relation to COVID-19 in Italy. JAMA 2020; 323: 1775-6.

25. Chen G, Wu DI, Guo W, et al. Clinical and immunological features of severe and moderate coronavirus disease 2019. J Clin Investig 2020; 130: 2620-9. 